\title{
Society and the State: the Problem of the State-adjusted History Structurization
}

\author{
Valentin Y. Lyubashits ${ }^{1}$ \\ Andrey Y. Mordovtsev² \\ Maria K. Bukharina² \\ Anastasia S. Polyakova² \\ ${ }^{1}$ Southern Federal University \\ ${ }^{2}$ Vladivostok State University of Economics and Service \\ E-mail: kafedra_tgp@mail.ru
}

Doi:10.5901/mjss.2015.v6n3s4p245

\begin{abstract}
In the present article the authors based on the analysis of the existing scientific literature critically examine different approaches to the solution of theoretical and methodological problems of the state-adjusted history structurization, offer their vision of the theory of evolution of the state organization of society. In particular, the subject of analysis in the article is the theory of Johan Goudsblom, Karl Popper, R. Nisbet, Marx, Engels and others. The paper argues that the evolution of the state as a political institution is caused by the necessity of solving the society problems, which require the development and introduction of qualitatively new management resources. Evolutionary aspect of management resources stands for the differentiation of the structural components of the state and their regulatory integration. At the same time functional and organized state embodies the type of activities that meet the needs of society for self-preservation and purposeful organization. From the perspective of the authors, each new evolutionary phase of development of the state as a political and legal institution is not only a more efficient way of performing old functions, but also the emergence of new, enhancing opportunities for the development of other structural components of the state. All this contributes to a new system of functions and the formation of a new historical type of a state.
\end{abstract}

Keywords: state, society, political process, evolution.

\section{Introduction}

The problem of the evolution of the state as a political and legal institution is a classical one for political science. In the scientific literature there are a lot of ways to describe the evolutionary typology of the state organization, which is associated with the assumption of variation, which is happen to be by a certain logic of fromation and the development of political institutions. Analyzing the question of the essence of statehood, it is necessary, in our point of view, to find the fundamental principle of its system unity. The main elements of statehood are "relatively isolated parts of the state structure, possessing a certain authority and autonomy" (Chirkin, 2000, p. 124). However, the genetic level of statehood as a characteristic of its inherent properties cannot be determined only by the nature of authority concentrated in the bodies of the state. The statehood is influenced by set of social relations that allow its elements and letter the state itself to be formed.

It should be noted that, in the narrow sense, the statehood can be regarded as a synonym for the state in general, the state of a particular historical type, as the structure of authority and authoritative relations in the state, i.e. the system of institutions and rules of their interaction determined by the Constitution. We will consider the statehood in wide sense through the mutual connection of its elements and public relations, functions, institutions, ideology, law, economics, culture, etc., mediating the general features and characteristics of the state.

Considering the state system in wide sense, we do not confine ourselves only to the state (political) and legal structures, but examine the relationship of the structural elements of the state, law and civil society institutions.

In the legal and political science literature problems of the state evolution as a political and legal institution, the analysis of its nature and functioning are always foreground.

Today there are a lot of ways to describe the evolutionary typology of state organization, different alternative versions. And that's not the point in building strict evolutionary scheme, but in allowing some variation, which is still 
happen to be by a certain logic of formation and development of political institutions. It is important to us to consider a number of ideas and approaches being put forward by modern scholars and concerning the largest stages and periods of political genesis.

Examination of the historical past in terms of chronology and stadial development is centuries-old. Plato in the "Laws" started the discussion of diversity of political institutions with the lowest levels of social organization. The notion of "process" was used as a basis for the development of the notions of "phases" or "stages". The "process" is considered as a sequence of changes that involve the transformation of something from one phase to another. That is, each "stage" or "phase" is a transition in the forward movement. It consists of small processes and is, ultimately, the large part of processes. In this case, the process does not preclude distinguishing of stages in social development.

\section{Literature Review}

The theory of stages or phases has not gone unnoticed for critics, the most striking of which are Popper and R. Nisbet (Nisbet, 1969 \& Popper, 1993). Johan Gudsblom in his work, which will be discussed below, noted that the tradition of building phase models (From Plato and Aristotle to Marx and Spencer) is criticized for the following reasons: first, they lack the historical specificity and therefore the verifiability; second, they blend factual and regulatory affirmations; third, they are based on the notion of inevitability and teleology. In the last decades two more items were added to that list: fourth, they are unable to explain the transition from one stage to another; and fifth, they actively disclose the experience of Western Europe and North America, i.e are "Eurocentric» (Goudsblom, 1996, p. 20).

One can agree with J. Goudsblom that stadial models have disadvantages along with advantages. At the issue, because of the small empirical representation, they may be unverifiable. Construction of general schemes of social evolution is often carried out with chronological accuracy.

The advantages include the absence of the primary spatial limitations. One of the most significant metamorphosis occurred in recent years with stage models is reorientation from "phases" and "stages" to "processes". This made it possible to remove the claims of critics of the theory of stages in case of its insolvency in explaining the transition states between the stages and "Eurocentrism."

One of the predecessors of modern theoretical typologies of history structurization is a formation-stadial approach. This approach is one of the most serious attempts to create a comprehensive natural-historical theory. Marx and Engels were the authors of that theory.

Immediate material circumstances of life have been recognized as only and absolute reality. The main postulate is expressed in the formula: "the mode of production of material life conditions the social, political and intellectual life processes in general" (Marx \& Engels, 1981, p. 6-7).

Primary and absoluteness of material production of life leads to the creation of a certain dependence of the political superstructure on the economic basis: "In the social production of their life, people enter into definite, necessary, and independent of their will relations - productive relations which correspond to a definite stage of development of their material manufacturing abilities. The totality of these productive relations constitutes the economic structure of society, the real foundation, on which a legal and political superstructure arises and to which definite forms of social consciousness correspond" (Marx \& Engels, 1981, p. 8). Thereby it is emphasized that the state, politics, political institutions are caused by the economy. Despite some signs of what is capable of exerting opposite effects on the economy, Marxism singles out the main thing: there is the essential dependence of the political institutions of the economy, the logic of state forms development is determined by the dynamics of the manufacturing abilities, method of production and productive relations.

"The manufacturing abilities ... form the basis of the whole story." This story includes three successive stages of world development: primary or archaic; secondary, or economic, and tertiary, or communist. The Marxist idea of the stages of development of the manufacturing abilities was the key one in the conceptualization of the concept of social formation, which has resulted in typological fixation and formulation as a stage of world development. Marxism requires a clear distinction of formations associated with the type of manufacturing, interformational and intraformational stages associated with the methods of production, as well as smaller stages, not only related to the types of production relations, but also included aspects of the organization of labor, technology, production, distribution, etc. (Lyubashits, Mordovtsev \& Mamychev, 2010; \& Mamut, 1989).

Numerous followers of Marx and Engels, by virtue of all sorts of circumstances, including incorrect translation of Marx in Lenin's work "What is the "Friends of the People" and How do They Fight against the Social Democrats?" of the era of economic society formation as an "epoch in the history of economic formation of society", contributed to the emergence of so-called pentamer (pyatichlenka). Marxist interpretation of politogenesis was extremely tenacious and is 
reflected in numerous neo- and post-Marxist studies. N.D. Kondratiev's concept of cycles is close to formation-stadial approach of Marxism. In a cyclical basis of history socio-economic formations, steps and stages of development of human society easily implant.

The structure of the Kondratiev cycles (cycle length is 40-60 years) is composed of two parts waves: buoyant wave and bearish wave. The buoyant wave is a period of prolonged prevalence of high economic conditions in the world economy. Bearish wave is a period of prolonged dominance of low economic conditions.

Long Kondratiev waves allow to consider not only the cycles of the state of the world, but also a manifestation of technological, economic, political and social changes occurring within such a wave or cycle.

One of the experts in the field of Kondratiev waves $\mathrm{G}$. van Room outlined a themed series of social life, which can be investigated through the following paradigm: social stratification, social mobility, revolution and reformism, the development and dissemination of different ideologies - from liberalism to fascism, changes in religious beliefs, democratic change and others. (Room Van, 1984, p. 237-244).

In the context of the Kondratiev paradigm waves of the various intervals - from 3-5 years to 1000 years (Pashinsky, 1994) are examined; for individual regions temporal distance of their action are marked (Andre Gunder Frank, Barry Gills and George William Modelski); the political dynamics is described (Umov \& Lapkin, 1992). Andre Gunder Frank in joint work with Barry Gills reveal the Kondratiev cycles of upturn and recession in the epoch of the Middle Ages and antiquity, which in a certain way structures the world history, setting five thousand years length of the world system against Wallerstein five hundred years length of European systems.

The driving force of the world system development is the accumulation of surplus value or capital associated with the change of hegemony and different combination of market and government.

Frank and Gills in addition to the economic situation consider the rise and expansion of the empires, establishment of the links between them, exchange activation or disintegration of empires and world-system connections.

Another expert in the field of social evolution analysis of world systems and long-term geopolitical cycles $\mathrm{J}$. Modelski in own way structures the scheme of world history. Evolution is divided into four main stages: variation, cooperation, selection and conformation. Transitions from one stage (era) to the other are explained by the exhaustion of innovative impulses that had previously dominated and the preparation of new products of innovations.

Thus, innovative transition from the first era (3200 - 1200 B.C.) to the second one (1200 B.C. - 1000 A.D.) was associated with the formation of multiple cultures and characterized by the proliferation of cities-states, a small number of large empires, etc.

Rather original approach to periodization of the historical development of society was offered by Johan Goudsblom in his work "The History of Mankind and the Long-term Social Processes in the Synthesis of History and Phaseology» (Goudsblom, 1996, p. 22-23). In its research the main "Catalysts" (Fire control; agrarization and industrialization) as a kind of ecological transformations that are dominant at a particular stage of development are highlighted. Then four successive steps are distinguished:

1. The stage when there is no society with control over fire, or agriculture, or industry, or X ( $X$ stands for relative human achievement - statehood, writing, religious institutions, etc.).

2. The stage when some societies have control over the fire, but no one has no agriculture, no industry or $X$.

3. The stage when at least some societies have control over the fire and agriculture, but no industry or $X$.

4. The stage when at least some societies have control over the fire, agriculture and industry, but none have $X$.

If we fill $X$ with such epochal innovation as the state (in the sequence from the less developed and simple to more complex and advanced types of political organization), we will obtain an effective tool for comparison and coordination of a wide variety of periodization.

A simple four-step criterion is introduced. For example, for the transition from communal autonomy to the state take the innovation (X) as a chiefdom: 1 ) this achievement is present in non social community; 2 ) there is a chiefdom in a social community; 3 ) some social communities has a chiefdom; 4) chiefdom is present in all social communities.

This life cycle of stages completes with the advent of the fifth stage, when some social community no longer requires such a form of social organization as a chiefdom. It is replaced by another innovation: a specific form of political organization - the traditional state. Traditional state comes into its own life cycle. Such an explication may be applied to other types of state forms.

In reviewing the various attempts of stagial structuring of models on must not ignore the researches of domestic science - Orientalist I.M. Diyakonov book "Paths of History" (1994). The author suggested stadial model of the history, including eight phases: primeval, primitive communal, early antique, Imperial antique, medieval, the stable-absolutist post-medieval, capitalistic and post-capitalistic.

The scientist in his periodization starts from the basic Marxist positions and states it himself: "From the point of 
view of causality the theory of socio-economic formations, scheduled by Marx more than a hundred years ago (1859) and in the deformed form formulated by Stalin in 1938 has advantages. According to this theory, the manufacturing obilities, i.e the technology in combination with its producers as a social category, develop as long as the existing social relations of production correspond with the needs of their development " (Dyakonov, 1994, p. 6). Dyakonov believes that in the late twentieth century the Marxist theory of history, reflecting the realities of the nineteenth century, "is hopelessly outdated." He tries to take into account new factors, namely the level of technology and the state of socio-psychological processes. To establish new relations of production, it is necessary, in his opinion, "to bring innovative technologies, in particular technologies for armament production" (Dyakonov, 1994, p.10).

The transition from one type of economy to another and then - from one system of social relations to the other must be accompanied by a change of social values. Significant role is given to the role of military equipment and military science in general. This is important from the point of view of military affiliation with the political structure of the organization as a whole.

Thus, the level of technology and the state of socio-psychological processes is a criterion for a "change of the principle of social relations" or the nature of state system. Exactly these factors contribute to the change of upturns and declines both within a given phase and between them.

Only in the third Diakonov phase (early antiquity), the system of society management is institutionalized, gets generally recognized structure, enforcement machinery and becomes a state.

The phase transition to the primitive community crowned chiefdom (The second phase of the primitive communal). Public institutions typologically belong to the primitive community (The third phase).

In every single period of history societies of different phases of development co-exist, and in a single phase different societies. This indicates that in every single period in the history societies of different phases of development coexist, but in a single phase, different societies possess approximately equal opportunities (Parity) and the effectiveness of their political and legal modes.

About these discontinuities and inconsistencies between the generations of political systems, creating difficulties in interaction chronopolitically different in times, but calendarly compatible modern political systems (llyin, 1999).

It is interesting that the typology of world-systems proposed by Christopher Chase-Dunn and Thomas Hall (ChaseDunn Ch \& Hall, 2001), in the aspect we are interested in largely consonant with the periodization of Dyakonov. In comparing the two approaches we find out that the third Diakonov phase (early antiquity) corresponds to the primary state world systems which include Mesopotamia, Egypt, the Indus Valley, the valley of the Ganges, China, pre-Columbian Mexico and Peru. The fourth phase - the phase of Imperial Antiquity - corresponds to primary empires, into which autonomous states were united by conquest (Akkad, Egypt, Magadha, Zhou, Teotihuacan, Huari), and to partly multicenter, consisting of empires, states and peripheral regions (Middle East, India, China, Peru).

The fifth phase, medieval, partially covers multicenter imperial and commercialized world systems based on the state in which the important aspects of marketability are developed. Note that the "way of accumulation" is taken as a criterion for distinguishing between world-systems. Sixth, seventh and eighth phases are also corresponding.

For Chase-Dunn and Hall in historical development analysis the problem of the origin and development of chiefdoms and the state from the less hierarchical structures based on kinship of societies was very important. In the periodization they attempted to identify the importance of intersocietal processes and structures (world-systems) in the "core - periodization" aspect.

An essential aspect of the conceptualization of world-systems is the revelation of the effects of different types of interactions over a long distance for local societal structures. It is interesting that the key indicator that allows to provide the domination of the nucleus, where the technology of authority is developed the most, is, as for Dyakonov, a specialized military organization, rear and logistics, strategy and weapons, as well as organizational technique for managing remote provinces and tribute and taxes collecting (Chase-Dunn \& Hal, 2001, p. 436).

On their own question: "What are the similarities and differences between the sequence of processes of political centralization and decentralization in various kinds of world-systems?" the authors answer with their own formulation of the hypothesis. It consists in the fact that, first, when the centralized empires improve the technique of authority, peripheral regions lag behind in their development; and, second, the peripheral regions more quickly assimilate social and technological features of the regions of the nucleus, as long-distance trade becomes more intense and based on commodity relations (Chase-Dunn \& Hall, 2001, p. 437). Thus, the Chase-Dunn and Hall specify the conditions and nature of the influence of society, leaders (the nucleus) to other societies (periphery) within the world-system. 


\section{Methods and Materials}

While studying the problems stated hereinbefore general scientific methods of knowledge were used: analysis, synthesis, comparison, analogy, deduction, induction, abstraction. Moreover such methods as functional-structural, comparativelegal, sociological and legalistic were applied. It should be noted that the consideration of the processes of state-adjust history structurization was based on the principles of system analysis which are used to solve the problem of the genesis and evolution of the state as a political and legal institution of society.

The principles of the system analysis of the evolution of the state are:

- the principle of social conditioning of the genesis and evolution of the state, consisting in solving adaptive problems of society, requiring new management resources;

- the structural-functional principle, consisting in studying differentiation of the structural components of the state and their regulatory integration that allow to perform innovative public functions that characterize the emergence of a evolutionary new type of state;

- the exogenous-endogenous approach in which intrasocial reasons of the national state origin and international causes of the transition from a feudal to a national type of state are examined;

- the historical approach consists in studying process of formation, distribution and consequences of evolutionary types of state.

An agreement on the co-existence of state formations and stages of development in one and the same historical period is considered to be common for concerned typologies. In this case, the formation of states is a clear watershed in the development of society. State is a politically structured society with specialized institutions, including the military and bureaucratic ones performing control and monitoring functions.

\section{Findings and Discussion}

The concept of "political evolution" is taken from the work of Dutch researcher, a renowned expert on evolutionism H.J.M. Claessen (Claessen \& Velde Van, 1985). Basing on multiline evolutionism Claessen tried to explain cyclical development and those cases where at different stages of evolution similar political structure appear. Evolution is a process of structural reorganization in time. The result is the emergence of some form, structure that is qualitatively different from the previous form. He established that similar political organizations (state or chiefdom) suddenly appear in various regions of the world and in different evolutionary streams. In search of a solution to this paradox Claessen drawn to the idea of Julian $\mathrm{H}$. Steward, who long before tried to explain the appearance of patriolocal groups in a number of companies that are not related to each other. The appearence of disparate socio-political structures Steward explained by the presence of similar cultural forms in these groups. Attention is drawn to the idea of Claessen and his co-author Austen that in order to maintain law and order, to preserve the territorial integrity of the country and other such organizational structures are required that are forced to find effective and functionally successful solutions fast. Here a reasonable functional argument is put forward (Claessen \& Austen, 1996). Each political organization goes harsh ordeal of efficiency and by virtue of this, there is little functionally suitable institutions. Claessen believes that evolutionary change is the result of a complex interaction of several factors, namely: economic, ideological, demographic and socio-political.

Structure, periodization proposed Novosibirsk researchers N.S. Rozov not radically different from the academic tradition of politogenesis studying, but it is rather innovative and demands attention. Rozov set the task of improving and restructuring of conceptual in explaining and understanding of history.

Based on his enough extensive philosophical and methodological studies (Rozov, 1992), he formulates a set of requirements for the periodization of the history and politogenesis: the principle of substantiality (periodization should be directly related to the main characteristics that define the qualities that define the specificity and stability of the different parts of the historical-political reality, as well as to the strongest factors (reasons, driving forces, patterns) of historical changes in these parts (Rozov, 1995); the principle of temporal comparability (division of the periods of history on the basis of based conceptually homogeneous and comparable criteria); the principle of spatial comparability (really existing diversity of historical forms, the obvious differences in the rate of historical changes taking into consideration); the principle of comparability of paradigms (conceptual structure of periodization should be comparable with the key categories of the most advanced and productive macrohistorical paradigms); the principle of flexible traditionalism (Rozov, 2001).

According to Rozov the substantial criterion of periodization is in the basic types of a variety of modes changing. Social mode, for example, includes the regular military, political, economic, moral, legal and other interactions. The character of the era is determined by the strongest dominant regime, and it is explicitly or implicitly presented in many 
attempts to structure the history of mankind, starting with Hegel and Marx. Under the dominant regimes the author understands "their higher efficiency over a wide range and this efficiency manifested in the relentless spread through repression and assimilation of competing regimes" (Rozov, 2001, p. 247). Rozov introduces the concept of "type attractor", which is defined in respect of structural approach as a mode complex which is stable within a certain range of conditions.

In the conceptual construction proposed by Rozov the scheme of shifts of dominant regime and mode complexes (types - attractors) is the most important element. Criteria for selection of factors of dominance consolidate the relation of the growth of the importance of political regime in the transition state and society from one phase to another.

Note that a noticeable impact on the allocation of factors of domination was made by the work of American political anthropologist R. Carneiro who in order to identify a political leader identified 14 categories. Of these, the category of "political organization" is the determining criterion of regime efficiency.

Thus, basing on Steward, Claessen idea of stages of political evolution, Carneiro workings-out, Gellner general history structure, I.M. Dyakonov's and others works, Rozov offers his perfectly typical scheme including six phases of development of society, of which four are state-adjusted. The third phase - a "society of early statehood"; the fourth - a "society of mature statehood"; the fifth - a "society through statehood" and the sixth - a "sensitive society" (the developed capitalism with liberal and corporate-state versions). Here also mentioned the basic state establishments in a particular phase of development of society. Each type-attractor or mode complex possesses its level of political evolution (the factor of universal value). The development of political structures and institutions determine the other factors of domination, which are grouped into factors of geopolitical, geo-cultural and geo-economic domination.

For our study it is the most relevant to select factors of dominance, or indicative criteria, which are correlated with the ideas of some scholars discussed above of the phases and the development of society, of the nature of the transition from one phase to the other, and of the reasons of dominance.

In its ideal-typical building the society, according to Rozov, is a set of human groups with the unity of the structures of authority, moral and / or legal rules, the unity of the order of exchange and distribution, the unity of the language or languages of social interaction.

But such criteria meet the advanced form of statehood, in particular, the nation state. Considering the aspect that the basic modes are political, legal and economic, we can define the state-adjust society as a set of human groups with the unity of the structures of authority, the rule of law and the common unity of order, exchange and distribution.

Despite of different ways of statehood forming, everywhere we find the established system of authority (political regime), which regulates the interaction between people (legal and moral mode), the procedure for the exchange of material goods and services and their distribution (economic mode). For communication and social interaction one needs a common language (cultural mode).

The first statehood in the world that has arisen in the Ancient East (Egypt, Babylon) was characterized by special laws, due to the specifics of the Egyptian, Babylonian and other contemporary civilizations (History of political and legal doctrines, 1985), and the ancient states of ancient Greece and Rome - examples of state that emerged, developed, reached the height of civilization and deadlocked within a given culture - Greek and Roman; and feudal states, which were characterized by their peculiar traits, and all other forms of government is inherent in the basic unity of the social and cultural modes. If the unity of the basic modes is broken one can talk about such a society in terms of "falling states" or "failed states". Modern specialists have counted forty-one state, which can be categorized as falling or failed states. The vector of the development of these countries shows their rapid social, economic, political and intellectual degradation. Often the governing board simply leads to the extinction of their own people (Rwanda, Somalia, etc.). One of the parameters of such formations is the inability of the leadership of these countries to ensure basic human rights in their territories.

\section{Concluding Remarks}

The problems of structuring of state-adjust history are very complex, primarily because of the huge variety of social, political, government forms, varying tempo of politogenesis. Isolation of the stages of development of political institutions (statehood) is complicated by the uncertainty of the common units of analysis, terms and concepts regarding the different paradigms of structuring and periodization of history.

Analysis of the evolution of society through the change of combinations of distinct structural features which differ the society from the preceding one, is carried out in this paper in the basis of Steward, Claessen individual ideas of concepts of history structuring, Carneiro workings-out, Gellner history structure, Rozov general conceptual approach. Although the conceptual schemes of these authors do not offer definitive solutions of the problems of periodization of 
historical and public process, but represent an important step towards the knowledge of the internal structures relations (social processes and patterns) and external structures (the division into historical intervals). It is obvious that the review and classification of political formations (the State) largely reflects the values of the classifiers.

Consideration of different points of view on the structuring of the state-adjust history has shown the importance of the problem of the basic criteria for periods distinguishing. Statement of the society's transition from one phase of state development to another requires the allocation of basic criterion or factor - the level of political development, which, in our opinion, is universal in its significance.

The essence of any historical period which discloses the source of changes, the decisive force that causes the transformation of all other sectors of society is the growth, distribution and retention of dominant position of the most efficient, in terms of the period, political regime.

\section{References}

Ilyin, M.V. (1999). Choice of Russia: myth, fate, culture // «Via Regia» (Moscow). № 1-2

Lyubashits, V.J., Mordovtsev, A.Y. \& Mamychev, A.Y. (2010). The Theory of the State and Law. Rostov-on-Don.

Dyakonov, I.M. (1994). Ways of History. From an Ancient man to the Present Day. M.

History of Political and Legal Doctrines. Ancient World, 1985, ed. by V.S. Nersesyants. M.

Mamut, L.S. (1989). Marx as a Theorist of the State. M.

Marx, K. \& Engels F. (1955-1981). Works. Moscow. Vol. 13.

Popper, K. (1993). The Poverty of Historicism. M.: Progress.

Pashinsky, V.M. (1994). Cyclicity in the History of Russia (from the perspective of social ecology) // Polis. №4.

Rozov, N.S. (1992). The Structure of Civilizations and World Development Trends. Novosibirsk.

Rozov, N.S. (1995). The Possibility of Theoretical History: Meeting the Karl Popper Challenges // Problems of Philosophy. № 12.

Rozov, N.S. (2001). Towards the Substantiation of World History Periodization. History Structures // World time. Ed. 2. Novosibirsk.

Umov, V.I. \& Lapkin V.V. (1992). Kondratiev Cycles and Russia: Reforms forecast // Polis. № 4.

Chase-Dunn Ch. \& Hall, T. (2001). One, Two, Many World-systems // World time. Vol. 2. Novosibirsk.

Chirkin, V.E. 2000. Political science. M.

Goudsblom, J. (1996). Human History and Long-Term Social Processes: Toward a Synthesis of Chronology and Phaseology/l Goudsblom J., Jones E.L, Mennell S.The Course of Human History. Economic Growth, Social Process and Civilization. M.E. Sharpe, N.Y. Ch.1.

Claessen, H.J.M., Velde, P. \& Smith, M.E. (1985). Development and Decline. The Evolution of Sociopolitical Organization. South Hadley, MA: Bergin and Garvey.

Claessen, H.J.M. \& Austen, J.G. (1996). Ideology and the Formation of Early States. Leiden; Brill.

Nisbet, R. (1969). Social Change and History. N.Y.: Oxford Univ. Press.

Room, Van C. (1984). Historians and Long Waves //Long Waves in the World Economy. L. 
ISSN 2039-2117 (online) ISSN 2039-9340 (print)
Mediterranean Journal of Social Sciences MCSER Publishing, Rome-Italy
Vol 6 No 3 S4 May 2015 